\title{
A Semantic Network Analysis of the International Communication Association
}

\author{
MARYA L. DOERFEL \\ University of North Carolina at Charlotte \\ GEORGE A. BARNETT \\ State University of New York at Buffalo
}

\begin{abstract}
This article examines the structure of the International Communication Association (ICA) through semantic network analysis. Semantic network analysis examines the relationships among a system's components based on the shared meanings of symbols. Galileo analysis and Quadratic Analysis Procedure revealed that the semantic network for ICA based on paper titles presented to its divisions and interest groups at its 1991 conference had a high degree of correspondence with the affiliation structure reported by Barnett and Danowski. Both networks differentiated the humanistic divisions from the scientific, the mediated from the interpersonal, and the theoretical from the applied. The results are taken to be an indication of the validity of the procedures employed for determining semantic networks. Finally, results are interpreted in regard to Human Communication Research's relationship to its parent organization, ICA.
\end{abstract}

emantic network analysis, similar to network analysis, is both a research method and a theoretical framework (Doerfel, 1998). Semantic network analysis differs from traditional network methods because it focuses on the structure of a system based on shared meaning rather than on links among communication partners. In other words, two nodes are connected in a semantic network to the extent that their uses of concepts overlap. The meaning-centered network approach stems from Monge and Eisenberg's (1987) call to enhance traditional network analysis by focusing on communication content. Semantic network

Marya L. Doerfel (Ph.D., State University of New York at Buffalo, 1996) is an assistant professor in the Department of Communication at the University of North Carolina at Charlotte. George A. Barnett (Ph.D., Michigan State University, 1976) is a professor in the Department of Communication at the State University of New York at Buffalo. An earlier version of this article was presented at the International Communication Association (ICA) meeting, Montreal, Quebec, May 1997. The authors would like to thank Bob Cox and ICA headquarters for providing the conference program and Ronald Rice, Ed Fink, and an anonymous reviewer for their comments on earlier drafts of this article. Correspondence should be addressed to Marya Doerfel, Department of Communication, University of North Carolina at Charlotte, Charlotte, NC 28223; e-mail: mdoerfel@email.uncc.edu.

Human Communication Research, Vol. 25 No. 4, June 1999 589-603

(C) 1999 International Communication Association 
analysis also has a theoretical foundation based on cognitive processes. Learning theorists argue that words are hierarchically clustered in memory (Collins \& Quillian, 1972). Thus, spatial models that illustrate the relationships among words are representative of meaning (see Barnett \& Woelfel, 1988). As a result, studies have turned to analysis of text with network analysis techniques (Danowski, 1982; Jang \& Barnett, 1995; Rice \& Danowski, 1993; Stohl, 1993).

The purpose of this article is to present a set of procedures for describing a semantic network analysis. The semantic network represents the structure of a system based on shared meaning. Second, the semantic network analysis of an organization is compared to a traditional network analysis of the same system. Specifically, the article (a) describes the relational structure of International Communication Association (ICA) based on semantic network analysis and (b) validates the semantic network procedure by examining its relationship to the structure resulting from a traditional network analysis that is based on shared affiliations, as described by Barnett and Danowski (1992).

Two requirements for assessing the validity of a set of operations are (a) a measure of association between the procedure's results and the results of a different set of procedures that are theoretically related and (b) an explanation of the strength of the association. The theoretical justification for the relationship between the semantic network and the network based on affiliations is provided below. Indicators of the strength of association between these two procedures are provided in the results section of this article.

One explanation why a network based on affiliations and one based on meaning should be significantly related comes from the literature on social influence process (Feeley \& Barnett, 1997; Rice, 1993). This literature suggests that individuals' attitudes and beliefs are a function of the information received from socially proximate individuals. In this case, attitudes toward communication research may be expressed by conference paper titles. Proximity is measured as shared memberships. Convergence theorists (Barnett \& Kincaid, 1983; Rogers \& Kincaid, 1981) argue that over time members of a social system converge on a common set of meanings as a result of joint interaction. That is, they are exposed to and influenced by the same information. In this case, membership in the same division or interest group results in the exposure of members to common information, either through social interaction or exposure to the same academic literature and conference presentations. As a result, conference paper titles would contain equivalent symbols. 


\section{METHOD}

Data

The data used to demonstrate the semantic network analysis were the titles of the papers presented at the annual meeting of ICA in 1991. Only those papers that were listed in the program that were presented specifically to divisions or interest groups were included. Panels, theme programs, and other association-wide programs were excluded from the analysis. Each title was labeled with its division or interest group. For those papers presented at a session sponsored by two divisions or interest groups, the papers were coded as belonging to both. The following is a list of the 13 divisions or interest groups.

1. information systems

2. interpersonal communication

3. mass communication

4. organizational communication

5. intercultural, international, and development communication

6. political communication

7. instructional and developmental communication

8. health communication

9. philosophy of communication

10. human communication and technology

11. popular communication

12. public relations

13. feminist studies

\section{Procedures for Semantic Network Analysis}

Semantic network analysis requires a content analysis of textual data to determine the most frequently used symbols. The analysis then provides the relationship among these symbols and how they covary with the members of the social system. Although this process traditionally has been conducted by hand, computer-based content analysis software has been developed and used to describe the semantic structure of textual data. For examples, see WORDLINK (Danowski, 1993) or CATPAC (Doerfel \& Barnett, 1996; Terra Research and Computing, 1994). This study employed CATPAC to analyze the paper titles.

CATPAC. CATPAC is a self-organizing artificial neural network computer program for analyzing text (Terra Research and Computing, 1994), such as open-ended question responses, news stories, speeches, or in this 
case, the titles of the papers presented at an ICA meeting. The software identifies the most frequently occurring words in a text and determines the pattern of similarity based on their co-occurrence. For example, mass and communication are two words that together create the concept mass communication. Thus, the program enables the organization of large bodies of text into meaningful conceptual groupings. The program reads through the text and identifies when specific words occur together. Thus, there is no need for preconceived categories and tests of intercoder reliability. It has been used in organizational culture (Freeman \& Barnett, 1994), marketing communication (Claffey, 1996), communication research to analyze presidential debates (Doerfel, 1994), and organizational structure based on shared semantic networks (Jang \& Barnett, 1995).

CATPAC operates as follows: It reads a body of text. The program then eliminates "stop words," which include a list of articles, prepositions, conjunctions, and transitive verbs that do not contribute to the meaning of the text (e.g., if, and, that, the, to, is). In addition, any words that distort the description of the text or have been shown to be problematic may be removed. CATPAC then counts the occurrences of the remaining words yielding the most frequently occurring words equal to the value set by the user. CATPAC then creates a words-by-words matrix with each cell containing the likelihood that the occurrence of one word will indicate the occurrence of another (the frequency of co-occurrence of any two words). This matrix is then cluster analyzed (Woelfel, 1993). In addition to the cluster analysis, CATPAC produces a visual plot of the symbols by multidimensional scaling (MDS) the co-occurrence matrix.

The neural network is constructed by reading a window $k$-words long that determines if any of the most frequently occurring words co-occur. The program then reads the next group of $k$ words, depending on the slide size. If the slide size is 1, CATPAC moves one word further in the text and reads the next $k$ words. This process is repeated until the entire text is read. From this windows-by-word matrix, the words-by-words matrix is constructed.

CATPAC also has the option of treating a block of text (instead of the words within a window) as a unique case. When using individual responses as the unit of analysis, a delimiter may be placed on the line following each case. The delimiter tells the program to treat each block of text in the same way as a window slide.

In this case, each paper title and the division or interest group name to which the paper was presented was treated as a separate unit of text. The data for the content analysis included (a) paper titles and (b) division and 
interest group identification. Each division was assigned a number from 1 to 13. Every time a paper title was entered into the data set, the division or interest group name was also recorded, thus creating a concept for each division. In other words, the division or interest groups' names were treated in the same way as other symbols. Thus, the names may be clustered and scaled with the words in the paper titles. In this way, it can be determined which words differentiate the divisions and interest groups.

\section{Procedures to Compare the Networks}

The data for 1991 were analyzed to compare the semantic network with the 1991 affiliation data analyzed by Barnett and Danowski (1992). The coordinates (from the MDS) for the divisions and interest groups were separated from the words in the titles, and the distances among just the divisions and special interest groups were determined. They were then rescaled by subtracting the frequencies of divisional co-occurrences from a constant that converted them to social distances on a scale of the same magnitude as the joint membership data (Barnett, 1988; Barnett \& Rice, 1985).

Quadratic assignment procedure (QAP). QAP (UCINET X) (Borgatti, Everett \& Freeman, 1992) was used to compare the two networks from 1991, the affiliations network from Barnett and Danowski (1992), and the semantic network. Krackhardt and Porter (1986) described the procedure as comparing two $\mathrm{N} \times \mathrm{N}$ matrices:

The procedure has several advantages over traditional linear model hypothesis testing. First it directly tests whether two matrices are similar to each other. The QAP tests take advantage of all the dyadic information represented in each matrix. That is, QAP compares each dyadic cell in Matrix A with the corresponding cell in Matrix B. The dyad is retained, then, as the appropriate unit of analysis. The second advantage of QAP is that it does not make parametric assumptions about the data. Ordinal, even categorical data can be tested without violating the distribution assumptions behind the procedure. (p. 52)

Galileo. The rescaled social distances were directly compared with the affiliation data using the Galileo program (Barnett \& Woelfel, 1988; Woelfel \& Fink, 1980). The two sets of coordinate values were rotated to congruence (Woelfel, Holmes, \& Kincaid, 1988), and the differences between the divisions and interest groups and the correlations among the dimensions from the two networks were calculated. In this way, the relationship between the two networks can be determined. 


\section{RESULTS}

Semantic Network Analysis: 1991

Table 1 presents the results from the CATPAC analysis. It reveals that 703 papers were presented to ICA at the 1991 conference. These papers contained 1,547 total words in their titles. Not surprisingly, the most frequent word in the titles was communication. It occurred 104 times or in $14.8 \%$ of the titles. Other frequently occurring words included media (66, $9.4 \%)$, culture $(46,6.5 \%)$, information $(44,6.3 \%)$, social $(43,6.1 \%)$, television $(41,5.8 \%)$, analysis $(39,5.5 \%)$, and politics $(37,5.3 \%)$. Table 1 also indicates how many papers were presented to each of the divisions and interest groups. For example, 100 papers were presented to the mass communication division and 77 to political communication. Table 1 lists the 30 most frequently mentioned words in the paper titles and the number of papers presented to each division.

A Ward's method cluster analysis was conducted among the words and divisional labels in the co-occurrence matrix, where each cell indicates the likelihood that the occurrence of a word will indicate the occurrence of another. Clusters that were identified include the following:

1. American, analysis, Division 13 , audience, news, television;

2. behavior, change, knowledge, impact, model, politics, Division 11, Division 7, effects;

3. Division 10, policy, development, Division 5;

4. case, study, Division 12 , public;

5. culture, Division 9, theory;

6. gender, differences, Division 2, social;

7. information, Division 1;

8. mass, Division 3, media;

9. communication, organizational, Division 4;

10. health, Division 8; and

11. Division 6, research.

Cluster 1 may be further divided into two subgroups: (a) American, analysis, Division 13, and (b) audience, news, television. Cluster 2 may be divided into four groupings: (a) behavior, change, knowledge; (b) impact, model; (c) politics, Division 11; and (d) Division 7, effects. Cluster 3 is composed of two subgroups: (a) Division 10, policy, and (b) development, Division 5. Cluster 4 also consists of two groupings: (a) case, study, and (b) Division 12, public.

The clusters denote the associations among the words and the divisions and interest groups. One indication of the validity of the employed procedures is the grouping of the division labels with the terms describing the content of the papers presented at the conference as expressed by 
TABLE 1

Semantic Network Analysis

\begin{tabular}{|c|c|c|c|c|c|}
\hline \multicolumn{3}{|c|}{ Descending Frequency List } & \multicolumn{3}{|c|}{ Alphabetically Sorted List } \\
\hline Word & $\begin{array}{c}\text { Case } \\
\text { Frequency }\end{array}$ & $\begin{array}{c}\text { Case } \\
\text { Percentage }\end{array}$ & Word & $\begin{array}{c}\text { Case } \\
\text { Frequency }\end{array}$ & $\begin{array}{c}\text { Case } \\
\text { Percentage }\end{array}$ \\
\hline $\mathrm{MC}$ & 100 & 14.2 & American & 16 & 2.3 \\
\hline Communication & 104 & 14.8 & Analysis & 39 & 5.5 \\
\hline Polycom & 77 & 11.0 & Audience & 15 & 2.1 \\
\hline Healthcom & 71 & 10.1 & Behavior & 17 & 2.4 \\
\hline Philcom & 66 & 9.4 & Case & 18 & 2.6 \\
\hline Media & 66 & 9.4 & Change & 14 & 2.0 \\
\hline ICDcom & 61 & 8.7 & Communication & 104 & 14.8 \\
\hline Orgcom & 60 & 8.5 & Comtech & 55 & 7.8 \\
\hline $\mathrm{HCT}$ & 55 & 7.8 & Culture & 46 & 6.5 \\
\hline Infosys & 52 & 7.4 & Development & 18 & 2.6 \\
\hline Culture & 46 & 6.5 & Differences & 16 & 2.3 \\
\hline IP & 42 & 6.0 & Edcom & 25 & 3.6 \\
\hline Social & 43 & 6.1 & Effects & 20 & 2.8 \\
\hline Femcom & 41 & 5.8 & Femcom & 41 & 5.8 \\
\hline Information & 44 & 6.3 & Gender & 15 & 2.1 \\
\hline Television & 41 & 5.8 & Health & 36 & 5.1 \\
\hline Health & 36 & 5.1 & Healthcom & 71 & 10.1 \\
\hline Politics & 37 & 5.3 & Icdcom & 61 & 8.7 \\
\hline Popcom & 34 & 4.8 & Impact & 17 & 2.4 \\
\hline Analysis & 39 & 5.5 & Information & 44 & 6.3 \\
\hline Study & 32 & 4.6 & Infosys & 52 & 7.4 \\
\hline Public & 28 & 4.0 & IP & 42 & 6.0 \\
\hline Mass & 27 & 3.8 & Knowledge & 13 & 1.8 \\
\hline News & 25 & 3.6 & Mass & 27 & 3.8 \\
\hline Organizational & 28 & 4.0 & $\mathrm{MC}$ & 100 & 14.2 \\
\hline Edcom & 25 & 3.6 & Media & 66 & 9.4 \\
\hline New & 24 & 3.4 & Model & 18 & 2.6 \\
\hline Effects & 20 & 2.8 & New & 24 & 3.4 \\
\hline PRcom & 19 & 2.7 & News & 25 & 3.6 \\
\hline Case & 18 & 2.6 & Organizational & 28 & 4.0 \\
\hline Behavior & 17 & 2.4 & Orgcom & 60 & 8.5 \\
\hline Impact & 17 & 2.4 & Philcom & 66 & 9.4 \\
\hline Research & 22 & 3.1 & Policy & 15 & 2.1 \\
\hline Theory & 21 & 3.0 & Politics & 37 & 5.3 \\
\hline American & 16 & 2.3 & Polycom & 77 & 11.0 \\
\hline Development & 18 & 2.6 & Popcom & 34 & 4.8 \\
\hline Differences & 16 & 2.3 & PRcom & 19 & 2.7 \\
\hline Model & 18 & 2.6 & Public & 28 & 4.0 \\
\hline Audience & 15 & 2.1 & Research & 22 & 3.1 \\
\hline Gender & 15 & 2.1 & Social & 43 & 6.1 \\
\hline Change & 14 & 2.0 & Study & 32 & 4.6 \\
\hline Knowledge & 13 & 1.8 & Television & 41 & 5.8 \\
\hline Policy & 15 & 2.1 & Theory & 21 & 3.0 \\
\hline
\end{tabular}

NOTE: Total words: 1,547. Total unique words: 43 . Total episodes: $703 . \mathrm{MC}=$ mass communication division. Polycom $=$ political communication division. Healthcom $=$ health communication division. Philcom $=$ philosophy of communication division. ICDcom $=$ intercultural and development communication. Orgcom $=$ organizational communication division. $\mathrm{HCT}=$ human communication and technology interest group. IP = interpersonal communication division. Femcom $=$ feminist scholarship interest group. Edcom $=$ instructional and developmental communication division. $\mathrm{PRcom}=$ public relations division . 


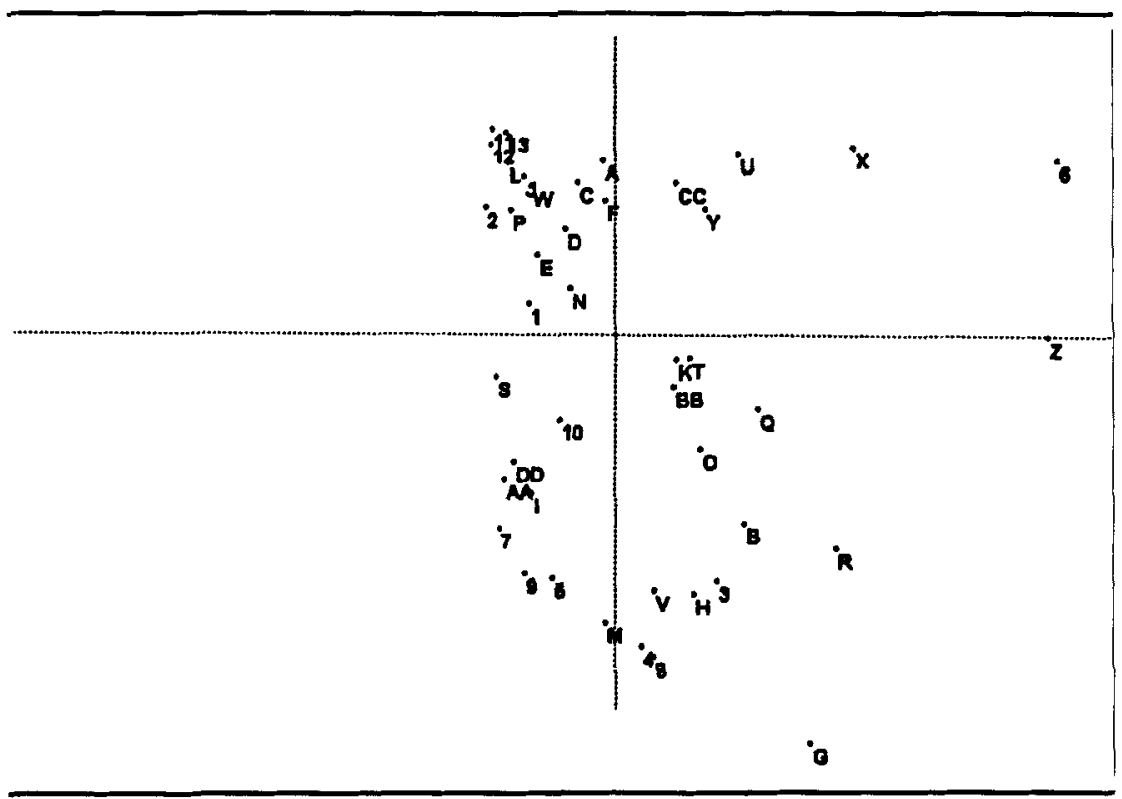

Figure 1: Two-Dimensional Plot of CATPAC Results

$\begin{array}{lll}\text { Key for words: } & \text { R Media } & \text { Key for divisions and interest } \\ \text { A American } & \text { S Model } & \text { groups: } \\ \text { B Analysis } & \text { T New } & \text { 1 Information systems } \\ \text { C Audience } & \text { U News } & \text { 2 Interpersonal communication } \\ \text { D Behavior } & \text { V Organizational } & \text { 3 Mass communication } \\ \text { E Case } & \text { W Policy } & \text { 4 Organizational communication } \\ \text { F Change } & \text { X Politics } & \text { 5 Intercultural/development } \\ \text { G Communication } & \text { Y Public } & \text { communication } \\ \text { H Culture } & \text { Z Research } & \text { 6 Political communication } \\ \text { I Development } & \text { AA Social } & \text { 7 Instructional/developmental } \\ \text { J Differences } & \text { BB Study } & \text { communication } \\ \text { K Effects } & \text { CC Television } & \text { 8 Health communication } \\ \text { L Gender } & \text { DD Theory } & \text { 9 Philosophy of communication } \\ \text { M Health } & & \text { 10 Human Communication } \\ \text { N Impact } & & \text { \& Technology } \\ \text { O Information } & & \text { 11 Popular communication } \\ \text { P Knowledge } & & \text { 12 Public relations } \\ \text { Q Mass } & & \text { 13 Feminist scholarship }\end{array}$

the papers' titles. For example, Cluster 2 groups politics with Division 6; Cluster 7 is composed of information and Division 1; Cluster 8 is made up of mass, media and Division 3; Cluster 9 contains organizational, communication and Division 4; and Cluster 10 groups health with Division 8. Clearly, the divisional focus is expressed in the titles of the papers presented to the various divisions.

Figure 1 presents a two-dimensional representation of the results of the multidimensional scaling of the co-occurrence matrix. It contains both the 30 most frequent words from the titles and the divisions and interest groups. A visual examination reveals that the words expressing the 
divisional focus are near the divisional labels. It should be noted that Figure 1 represents only a proportion of the variance among the terms and that any conclusions drawn from the figure should be viewed skeptically. The coordinates used to draw this figure represent the basis for the Galileo analysis described below. The coordinates for the 13 divisions and interest groups were separated from the words in the titles and the distances among just the 13 groups were retained for the analysis.

\section{Comparing the Semantic and Affiliation Networks}

The extent of the relationship between the semantic network and the one based on joint memberships among the divisions and interest groups was determined through QAP and Galileo.

QAP. By using QAP, the similarity between the two sociomatrices based on different measures, namely the affiliations matrix and the one based on shared word usage, is identified. The results of QAP reveal a significant correlation between the affiliation and the semantic networks. The QAP correlation was $r=.40, p=.03$. That is, both types of measures describe a similar underlying structure of ICA.

Galileo. The locations of the divisions and interest groups were extracted from the coordinates of the semantic network, and their distances were determined and rescaled. Using the Galileo program (Woelfel \& Fink, 1980), the two sets of coordinate values (affiliation and semantic) were rotated to a least-squares congruence (Woelfel et al., 1988). Then, the differences between the divisions and interest groups were determined, and the dimensions from the two networks were correlated.

Table 2 presents the rotated coordinates for the semantic network. The coordinates for the affiliational structure may be found in Barnett and Danowski (1992). Table 3 presents the differences in the divisions' and interest groups' relative locations between the two networks. The average difference between the two networks was 29.3 units. Health communication's location was the most discrepant at 54.5 units, followed by interpersonal communication (37.7), popular communication (33.3), and mass communication (31.6). Two dimensions of the networks' rotated coordinates are presented in Figure 2 that account for only $29.0 \%$ of the variance for the semantic network and $47.3 \%$ of the variance for the joint affiliation network. Thus, any conclusions drawn from the figure should be made with caution. However, an inspection of Figure 2 reveals a reason for the discrepancy between health communication's position in the two networks. Its members also tend to be members of the interpersonal and instructional and developmental communication divisions, yet the titles 
TABLE 2

Coordinates for Semantic Network

\begin{tabular}{|c|c|c|c|c|c|c|c|c|c|c|c|c|}
\hline & 1 & 2 & 3 & 4 & 5 & 6 & 7 & 8 & 9 & 10 & 11 & 12 \\
\hline Information systems division & -14.493 & 21.184 & -24.238 & -14.315 & -8.997 & -9.780 & 37.879 & -8.296 & 2.383 & -28.557 & -3.660 & 9.464 \\
\hline $\begin{array}{l}\text { Interpersonal communication } \\
\text { division }\end{array}$ & -32.536 & -28.480 & 2.213 & -8.502 & 37.722 & 12.023 & 9.609 & -7.455 & 3.540 & 16.671 & -5.127 & 11.261 \\
\hline Mass communication division & -2.153 & -.296 & .573 & -.679 & 2.599 & 3.763 & -2.798 & -3.061 & 2.824 & -8.094 & 9.045 & -41.365 \\
\hline $\begin{array}{l}\text { Organizational communication } \\
\text { division }\end{array}$ & -9.330 & 4.077 & 6.980 & -3.541 & -15.877 & -4.077 & 9.649 & .240 & -24.512 & 19.797 & -.981 & -5.698 \\
\hline $\begin{array}{l}\text { Intercultural and development } \\
\text { communication }\end{array}$ & 4.959 & -6.232 & -7.464 & -7.260 & 19.790 & -8.990 & -21.200 & 39.025 & -18.693 & -23.473 & -2.066 & 4.601 \\
\hline Political communication division & 8.086 & 14.229 & .950 & 24.172 & 18.455 & -12.005 & 9.025 & -4.176 & -11.181 & 12.869 & 11.359 & -12.454 \\
\hline $\begin{array}{l}\text { Instructional and developmental } \\
\text { communication }\end{array}$ & -13.521 & -24.240 & -1.359 & 45.179 & -27.240 & -4.777 & -4.430 & -7.055 & 1.079 & -9.271 & -4.773 & 9.435 \\
\hline Health communication division & -2.617 & -10.603 & -.056 & -13.616 & -12.199 & 7.531 & -5.174 & -.107 & 10.772 & -2.904 & 20.350 & -23.614 \\
\hline $\begin{array}{l}\text { Philosophy of communication } \\
\text { division }\end{array}$ & 28.930 & -.907 & -11.447 & -1.994 & 9.830 & -8.665 & 8.596 & 3.973 & 42.327 & 15.526 & -4.662 & 4.823 \\
\hline Human communication technology & -9.622 & 36.977 & -12.539 & -1.141 & -3.170 & 16.759 & -41.179 & -14.138 & 4.834 & 13.857 & -4.745 & 10.471 \\
\hline $\begin{array}{l}\text { Popular communication interest } \\
\text { group }\end{array}$ & 26.807 & -3 & -5 & & -9 . & 47 & 15.247 & 13. & -14.087 & & & 10.765 \\
\hline Public & -9.346 & 16.218 & 50.819 & -2.242 & -7.825 & -10.814 & .614 & 19.932 & 18.040 & -4 . & -4.747 & 11.007 \\
\hline Feminist scholarship interest group & 24.835 & -18.593 & .986 & -20.788 & -3.938 & -28.254 & -15.838 & -32.531 & -17.326 & -3.671 & -5.160 & 11.303 \\
\hline
\end{tabular}

Eigenvalues (roots) of eigenvector matrix

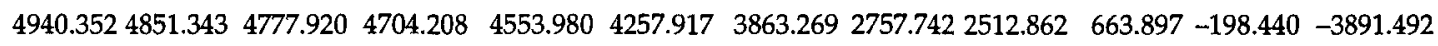

Percentage of variance accounted

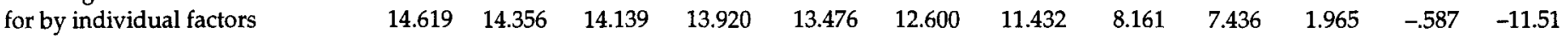

Sum of roots 33793.5302 
TABLE 3

Differences Between Divisions' and Interest Groups' Locations in Semantic and Joint Membership Networks

\begin{tabular}{ll}
\hline Information systems & 25.018 units \\
Interpersonal & 37.668 units \\
Mass communication & 31.600 units \\
Organizational & 24.989 units \\
Intercultural & 22.012 units \\
Political & 22.347 units \\
Instructional & 15.758 units \\
Health & 54.490 units \\
Philosophy & 28.492 units \\
Human communication technology & 30.608 units \\
Popular communication & 33.255 units \\
Public relations & 26.448 units \\
Feminist scholarship & 27.842 units \\
\hline Mean distance & 29.271 units \\
\hline
\end{tabular}

$$
\uparrow \Theta
$$

HCT

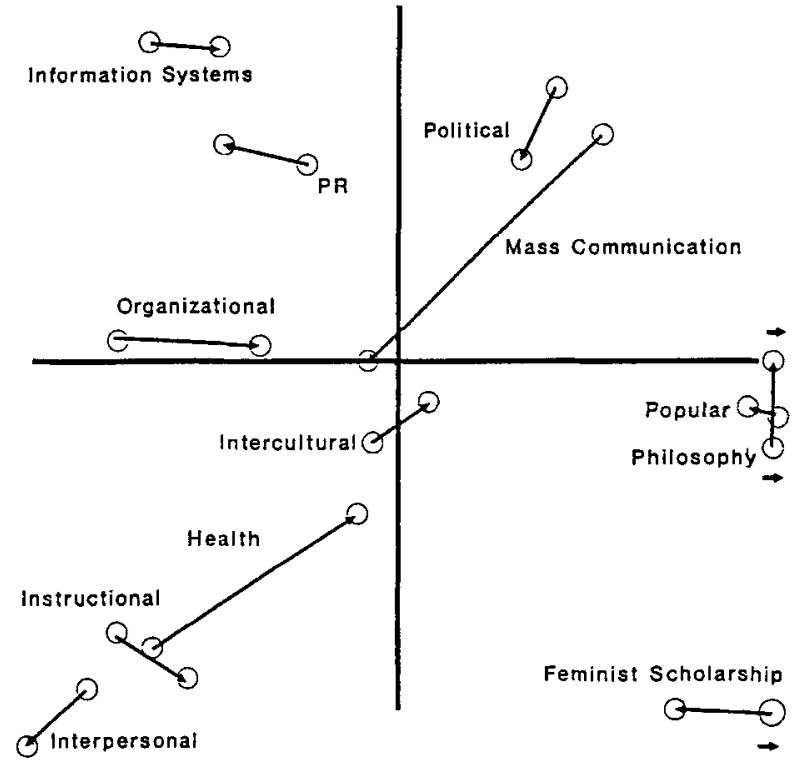

Figure 2: Two-Dimensional Comparison of Semantic and Affiliation Networks

NOTE: The short arrows indicate that the division or interest group's location nearest to the arrow is further from the origin of the space than it appears in the figure. The circle at the base of the solid arrow is location of the division or interest group based on its affiliations. The circle at the arrow point is the location of division or interest group based on work usage after the coordinates have been rotated to congruence. 
TABLE 4

Correlations Among Corresponding Dimensions From Semantic and Joint Membership Networks

\begin{tabular}{ccl}
\hline \hline Dimension & Correlation & $\mathrm{p}$ \\
\hline 1 & .901370 & .001 \\
2 & .949693 & .001 \\
3 & .916750 & .001 \\
4 & .972626 & .001 \\
5 & .565169 & .05 \\
6 & .844412 & .001 \\
7 & .933265 & .001 \\
8 & .891889 & .001 \\
9 & .952929 & .001 \\
10 & .942767 & .001 \\
11 & .154026 & $n s$ \\
12 & .628347 & .05 \\
\hline
\end{tabular}

of the research presented have similar words as the titles in the mass communication division.

Table 4 presents correlations among the dimensions. The correlations of the first four dimensions were all greater than $.90(p<.001)$, indicating that the same dimensions differentiated ICA's divisions and interest groups in both the semantic and the joint membership (affiliation) networks. Dimension 1 differentiated the humanities and scientific divisions and interest groups. Dimension 2 represents the mediated and interpersonal perspectives. Dimension 3 represents the theoretical and applied. Dimension 4 differentiates health communication and feminist scholarship from instructional and political communication.

\section{DISCUSSION}

The results indicate the two descriptions of the structure of ICA are similar. The QAP results indicate a significant relationship between the affiliations and semantic networks. The correlations between the first four dimensions from Galileo were all above 90 , indicating that these two procedures resulted in equivalent descriptions of the association. In other words, the high level of association between the two approaches may be taken as an indicator of the validity of the procedures presented for semantic network analysis.

This article describes the structure of ICA based on the titles of papers presented at an annual conference. However, it does not describe the structure of the field of communication in general. To do so, it is necessary 
to include the titles of papers presented to the other academic organizations, for example, the National Communication Association, Association for Education in Journalism and Mass Communication, and the International Association for Media and Communication Research.

This research examined the relationship between a semantic network and a membership affiliation network. It did not measure the actual social interaction of ICA members or scientific communication based on the pattern of authored citations. Furthermore, it measured affiliation with only one indicator-membership in ICA divisions and interest groups. Affiliation data may be gathered in a number of ways: where the individual went to school, academic lineage, in what journal the author publishes, and patterns of citation. Future research should measure the social interaction among ICA members, the pattern of their citations, and affiliations as suggested above.

Furthermore, future research should also consider structural changes over time. It should describe how the field of communication is evolving, indicating how the relations among the various substantive areas, as represented by ICA divisions, shift over time in response to changes in technology and in response to various social issues. Convergence theory argues that individuals involved in mutual interaction will, over time, develop a common set of meanings. Thus, to determine the validity of the causal explanation based on social influence processes and convergence theory, time-ordered data must be analyzed. Do the patterns of interaction among communication scholars result in the shared use of symbols and a common set of meanings for those symbols? And what is the lag between social interaction and the emergence of shared meaning? In this way, it will be possible to precisely determine the relationship between semantic networks and social interaction.

\section{Implications for $H C R$}

$H C R$ is an official journal of ICA. As such, the structure of the organization based on the subject matter presented at its annual conference should also be reflective of the areas covered in its primary research journal. The journal's statement of purpose indicates that all theoretical and philosophical perspectives are encouraged, and it reflects no particular methodological or substantive biases. However, based on the authors' impressions, HCR seems to focus only on a portion of ICA members' research topics. Draw a line from the top right to the lower left of Figure 2, starting in the area between mass and popular communication and extending to the area between interpersonal and feminist scholarship, and the region that $H C R$ covers from that which is published elsewhere would be demarcated. The journal tends to focus on topics to the left of the line. 
This raises the following questions: (a) Does $H C R$ ignore the scholarly research of some ICA members? and (b) should the journal expand its focus to become inclusive of the association's entire membership? ICA, however, also sponsors other journals, that is, the Journal of Communication and Communication Theory. Again, based purely on general impressions, Communication Theory tends to publish research from the right of the line, and the Journal of Communication publishes the entire range of scholarly activity of the field. Barnett and Danowski (1992) point out that the membership of ICA is composed of distinct subgroups, each with a unique substantive or epistemological perspective. The results reported here substantiate their findings using the titles of scholarly work presented to the sponsoring organization. Perhaps $H C R$ should not attempt to cover the entire spectrum of the field but instead continue to publish empirical research guided by a positivist epistemology.

\section{REFERENCES}

Barnett, G. A. (1988). Precise procedures for longitudinal network analysis. In G. A. Barnett \& J. Woelfel (Eds.), Readings in the Galileo system: Theory, methods and applications (pp.333-368). Dubuque, IA: Kendall/Hunt.

Barnett, G. A., \& Danowski, J. A. (1992). The structure of communication: A network analysis of the International Communication Association. Human Communication Research, 19, 264-285.

Barnett, G. A., \& Kincaid, D. L. (1983). Cultural convergence: A mathematical theory. In W. B. Gudykunst (Ed.), Intercultural communication theory (pp. 171-194). Beverly Hills, CA: Sage.

Barnett, G. A., \& Rice, R. E. (1985). Longitudinal non-euclidean networks: Applying Galileo. Social Networks, 7, 287-322.

Barnett, G. A., \& Woelfel, J. (Eds.). (1988). Readings in the Galileo system: Theory, methods and applications. Dubuque, IA: Kendall/Hunt.

Borgatti, S., Everett, M., \& Freeman, L. (1992). UCINET X: Network analysis software [Computer software]. Columbia, SC: Analytic Technologies.

Claffey, G. A. (1996, May). Customer feedback: Using content analysis to reduce uncertainty in a changing environment. Paper presented to the International Communication Association, Chicago.

Collins, A. M., \& Quillian, M. R. (1972). Experiments on semantic memory and language comprehension. In L.W. Gregg (Ed.), Cognition in learning and memory (pp. 117-138). New York: Wiley.

Danowski, J. A. (1982). A network-based content analysis methodology for computer mediated communication: An illustration with a computer bulletin board. In M. Burgoon (Ed.), Communication yearbook 6 (pp. 904-925). New Brunswick, NJ: Transaction.

Danowski, J. A. (1993). Network analysis of message content. In W. D. Richards \& G. A. Barnett(Eds.), Progress in communication sciences (vol. 12, pp. 197-222). Norwood, NJ: Ablex.

Doerfel, M. L. (1994, November). The 1992 presidential debates: A new approach to content analysis. Paper presented at the annual meeting of the Speech Communication Association, New Orleans.

Doerfel, M. L. (1998, Fall). What constitutes semantic network analysis? A comparison of research and methodologies. Connections, 21(2), 16-26. 
Doerfel, M. L., \& Barnett, G. A. (1996). The use of CATPAC for text analysis. Cultural Anthropology Methods, 8, 4-7.

Feeley, T. H., \& Barnett, G. A. (1997). Predicting employee turnover from communication networks. Human Communication Research, 23, 370-387.

Freeman, C. A., \& Barnett, G. A. (1994). An alternative approach to using interpretative theory to examine corporate messages and organizational culture. In L. Thayer \& G. A. Barnett (Eds.), Organization $\leftrightarrow$ Communication: Emerging perspectives IV (pp. 60-73) Norwood, NJ: Ablex.

Jang, H., \& Barnett, G. A. (1995). Cultural differences in organizational communication: A semantic network analysis. Bulletin de Methodologie Sociologique, 44, 31-59.

Krackhardt, D., \& Porter, L. (1986). The snowball effect: Turnover embedded in communication networks. Journal of Applied Psychology, 71, 50-55.

Monge, P. R., \& Eisenberg, E. M. (1987). Emergent communication networks. In F. Jablin, L. Putnam, K. Roberts, \& L. Porter, (Eds.), Handbook of organizational and management communication (pp. 204-242). Beverly Hills, CA: Sage.

Rice, R. E. (1993). Using network concepts to clarify sources and mechanisms of social influence. In W. D. Richards \& G. A. Barnett (Eds.), Progress in communication sciences (Vol. 12, pp. 43-67). Norwood, NJ: Ablex.

Rice, R. E., \& Danowski, J. A. (1993). Is it really just like a fancy answering machine? Comparing semantic networks of different types of voice mail users. Journal of Business Communication, 30, 369-397.

Rogers, E. M., \& Kincaid, D. L. (1981). Communication networks: Toward a new paradigm. New York: Free Press.

Stohl, C. (1993). European managers' interpretation of participation: A semantic network analysis. Human Communication Research, 20, 97-117.

Terra Research and Computing. (1994). The Galileo Computer Program [Computer software]. Birmingham, MI: Terra.

Woelfel, J. (1993, Winter). Artificial neural networks for policy research. Journal of Communication, 43(1), 63-80.

Woelfel, J., \& Fink, E. L. (1980). The measurement of communication processes: Galileo theory and method. New York: Academic.

Woelfel, J., Holmes, R., \& Kincaid, D. L. (1988). Rotation to congruence under theoretical constraints. In G. A. Barnett \& J. Woelfel (Eds.), Readings in the Galileo system: Theory, methods and applications (pp. 219-234). Dubuque, IA: Kendall/Hunt. 